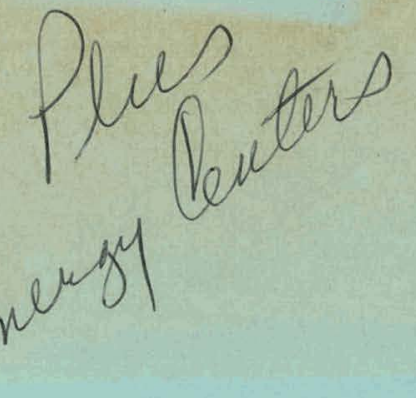

\title{
SEASONAL PERFORMANCE AND COST FACTORS OF OIL OR GAS-FIRED BOILERS AND FURNACES
}

\author{
A.L. Berlad, J. Batey, R. Hoppe, and F.J. Salzano
}

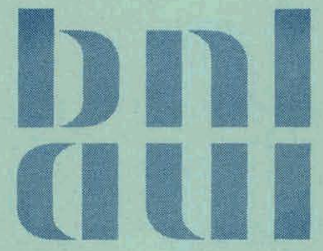

August 1976

DEPARTMENT OF APPLIED SCIENCE

BROOKHAVEN NATIONAL LABORATORY ASSOCIATED UNIVERSITIES, INC. UNDER CONTRACT NO. EY-76-C-02-0016 WITH THE UNITED STATES ENERGY RESEARCH AND DEVELOPMENT ADMINISTRATION 


\section{DISCLAIMER}

This report was prepared as an account of work sponsored by an agency of the United States Government. Neither the United States Government nor any agency Thereof, nor any of their employees, makes any warranty, express or implied, or assumes any legal liability or responsibility for the accuracy, completeness, or usefulness of any information, apparatus, product, or process disclosed, or represents that its use would not infringe privately owned rights. Reference herein to any specific commercial product, process, or service by trade name, trademark, manufacturer, or otherwise does not necessarily constitute or imply its endorsement, recommendation, or favoring by the United States Government or any agency thereof. The views and opinions of authors expressed herein do not necessarily state or reflect those of the United States Government or any agency thereof. 


\section{DISCLAIMER}

Portions of this document may be illegible in electronic image products. Images are produced from the best available original document. 
BNL 50572

(Energy Conservation - Buildings

and Industry - TID-4500)

\title{
SEASONAL PERFORMANCE AND COST FACTORS OF OIL OR GAS-FIRED BOILERS AND FURNACES
}

\author{
A.l. Berlad, ${ }^{*}$ J. Batey, R. Hoppe, and F.J. Salzano
}

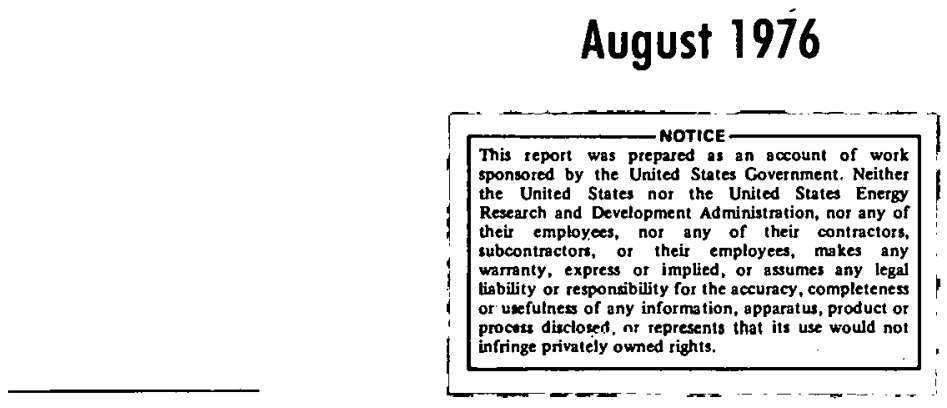

*College of Engineering and Applied Sclences, State University of New York, Stony Brook, N.Y. 11794

\section{DEPARTMENT OF APPLIED SCIENCE}

BROOKHAVEN NATIONAL LABORATORY UPTON, NEW YORK 11973 


\section{NOT I C E}

This rcport was prepared as an account of work sponsored by the United States Government. Neither the United States nor the United States Energy Research and Development Administration, nor any of their employees, nor any of their rontrartnrs, subcunu'ducturs, or their employees, makes any warranty, express or implied, or assumes

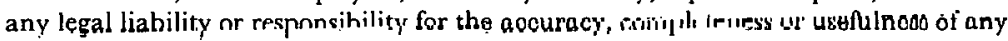
information, apparatus, product or process disclosed, or represents that its use would not infringe privately owned rights.

Printed in the United States of America Available from

Natiunal Technical Information Service

U.S. Department of Commerce 5285 Port Royal Road

Springfield, VA 22161

Price: Printed Copy $\$ 3.50$; Microfiche $\$ 2.25$

October 1976 850 copies 


\section{Abstract}

The seasonal operating cost of a small oil or gas-fired boiler or furnace depends upon the intrinsic merits of the device itself, the appropriateness of its capacity and cycle characteristics to the imposed load conditions, the weather characteristics and heat loss characteristics of the building being heated, and the control philosophy employed. The current study provides the bases for comparing quantitatively the seasonal operating costs of various specific space heating and/or domestic hot water systems, as influenced by the device specifics and device interaction with the space conditioned system that it serves. 


\section{Introduction and Background}

The cost effective performance of an oil or gas-fired boiler or furnace depends upon a number of factors. Some of these factors are characteristics solely of the boiler/furmace under consideration. ${ }^{1}$ other factors pertain to the coupling mechanisms (e.g.., water lines, air ducts, etc.) between energy conversion device and the conditioned space it serves. Still other factors pertain to the merits of the "sizing" of the energy conversion device and its appropriateness when measured against the enthalpy flow demands imposed by the structure it is required to serve. 2,3

one may assess the effectiveness of a structure's design and operating strategy in making optimum use of a given boiler/furnace system. Analyses with these emphases are given elsewhere. 1,3 The purpose of this analysis is to provide the bases for comparing. the seasonal operating costs of various specific space heating and/or domestic hot water systems, as influenced by the device specifics and device interaction with the space conditioned system it serves.

II. Enthalpy Balances and Seasonal Mass Flow of Fuel

A figure of merit for the seasonal performance of a given boiler/furnace system ultimately must measure the seasonal operating costs for the system, when compared to some standard, or ideal system. To derive such a figure of merit, we consider first the boiler/furnace hourly rate of enthalpy effluent. This is given by

$$
\dot{\mathrm{m}}_{\mathrm{f}} \bar{\eta} \Delta_{\mathrm{c}}=\mathcal{L}_{\mathrm{d}}\left[\frac{\mathrm{T}^{*}-\mathrm{T}_{\mathrm{c}}}{\mathrm{T}^{*}-\mathrm{T}_{\mathrm{d}}}\right]+\mathrm{H}_{\mathrm{O}} \quad \text {, for } \mathrm{T}_{\mathrm{c}}<\mathrm{T}^{*}
$$

Symbol definitions appear in a nomenclature section. We may also take the boiler/furnace (hourly rate of) design enthalpy effluent to be: 


$$
n_{f, d} n_{s} \Delta_{C}=\left(\mathcal{L}_{d}+H_{o}\right) a
$$

The "overfiring ratio" generally has a value, $\alpha>1$, reflecting considerations of domestic hot water supply. It has been shown elsewhere 2.4 that $\alpha$ should be taken as small as possible, in order to assure optimum overall efficiency $(\bar{\eta})$ values.

Note that for commonly encountered ${ }^{2,3}$ operating cycles (frame structures) one can correlate $\eta_{c}$ as a function of the ratio $\left(\dot{\mathrm{m}}_{\mathrm{f}} / \dot{\mathrm{m}}_{\mathrm{f}, \mathrm{d}}\right)$. Thus,

$$
\eta_{c}=\varnothing\left(\dot{\mathrm{m}}_{f} / \dot{\mathrm{m}}_{\mathrm{f}, \mathrm{d}}\right)
$$

where the functional dependence of equation (3) is determined in the laboratory for any given piece of apparatus. Inasmuch as 2,3

$$
\bar{\eta}=\eta_{c} \eta_{s}
$$

it follows that $\dot{\mathrm{m}}_{f}$ enters equation (1) in a nonlinear fashion. Combining (1) and (2) gives (for $\mathrm{T}_{\mathrm{C}}<\mathrm{T}^{*}$ ):

$$
\dot{\mathrm{m}}_{f}=\left[\frac{\dot{\mathrm{m}}_{\dot{f}_{,} \mathrm{d}}}{\alpha \eta_{\mathrm{C}}}-\frac{\mathrm{H}_{\mathrm{O}}}{\Delta_{C} \overline{\bar{\eta}}}\right]\left[\frac{\mathrm{T}^{*}-\mathrm{T}_{C}}{\mathrm{~T}^{*}-\mathrm{T}_{\mathrm{d}}}\right]+\frac{\mathrm{H}_{\mathrm{O}}}{\Delta_{C} \bar{\eta}}
$$

Thus, during any given hour characterized by $\mathrm{T}_{\mathrm{C}, i}$ ' the actual fuel mass flow rate is

$$
\dot{\mathrm{m}}_{f, i}=\left[\frac{\dot{\mathrm{m}}_{f, d}}{\alpha \eta_{c, i}}-\frac{\mathrm{H}_{o}}{\Delta_{c} \bar{\eta}_{i}}\right]\left[\frac{\mathrm{T}^{*}-\mathrm{T}_{c, i}}{\mathrm{~T}^{*}-\mathrm{T}_{\mathrm{d}}}\right]+\frac{\mathrm{H}_{0}}{\Delta_{c} \bar{\eta}_{i}}
$$

Given $\mathrm{n}_{i}$ hours per year which have a characteristic temperature, $T_{C, i}$ (where $T_{C, i}<T^{*}$ for all $i$ ) we may write the resulting total fuel usage

$$
\begin{gathered}
\dot{m}_{f, i} n_{i}=\left[\frac{\dot{m}_{f, d}}{\alpha \eta_{c, i}}-\frac{H_{0}}{\Delta_{c} \eta_{i}}\right]\left[\frac{T^{*}-T_{c, i}}{T^{*}-T_{d}}\right] n_{i} \\
+\left(H_{o} n_{i}\right) /\left(\Delta_{c} \bar{\eta}_{i}\right)
\end{gathered}
$$


Then, suming overall $T_{c, i}<T^{*}$ values, the total annual heating season fuel usage is obtained

$$
\begin{aligned}
M_{1}=\sum_{i} \dot{m}_{f, i} n_{i}=\sum_{i}\{ & {\left.\left[\frac{\dot{m}_{f, d}}{\alpha \eta_{c, i}}-\frac{H_{0}}{\Delta_{c} \bar{\eta}_{i}}\right]\left[\frac{T^{*}-T_{c, i}}{T^{*}-T_{d}}\right] n_{i}\right\} } \\
& +\sum_{i}\left(H_{o} n_{i}\right) /\left(\Delta_{c} \bar{\eta}_{i}\right)
\end{aligned}
$$

In order to obtain the corresponding total annual fuel usage $M_{2}$, for the nonheating season, we note that for $T_{C} \geq T^{*}$

$$
\dot{\mathrm{m}}_{f}^{*} \bar{\eta}^{*} \Delta_{\mathrm{C}}=\mathrm{H}_{\mathrm{O}}
$$

where $\bar{\eta}^{*}$ is a nonlinear function of $\dot{\mathrm{m}}_{\mathrm{f}}$. Equation (9) may be combined with equation (2) to give

$$
\dot{\mathrm{m}}_{\mathrm{f}}{ }^{*}=\frac{1}{\eta_{\mathrm{c}}^{*}}\left[\frac{\dot{\mathrm{m}}_{\mathrm{f}, \mathrm{d}}}{\alpha}-\frac{\mathscr{L} \mathrm{q}}{\eta_{\mathrm{s}} \Delta_{c}}\right]
$$

Equations (2) and (9) may also be used to obtain

$$
\left(\frac{\dot{\mathrm{m}}_{f}^{*}}{\dot{\mathrm{m}}_{f, \mathrm{~d}}}\right)=\frac{\mathrm{H}_{\mathrm{o}}}{\eta_{\mathrm{c}}^{*}\left(\mathrm{H}_{\mathrm{o}}+\mathscr{L}_{\mathrm{d}}\right)(\alpha)}
$$

where the total mass of fuel used during hours for which $T_{C} \geq T^{*}$ is given by

$$
\mathrm{M}_{2}=\dot{\mathrm{m}}_{\mathrm{f}}^{*} \mathrm{n}^{*}
$$

Thus, combining (11) and (12) yields

$$
\mathrm{M}_{2}=\frac{\mathrm{H}_{0} \dot{\mathrm{m}}_{\mathrm{f}, \mathrm{d}^{\mathrm{n}}}}{\eta_{c}^{*}\left(\mathrm{H}_{0}+\mathscr{Z}_{\mathrm{d}}\right)(\alpha)}
$$

The total mass of fuel used during the year is the given by, M, where

$$
M=M_{1}+M_{2}
$$


where $\mathrm{M}_{1}$ and $\mathrm{M}_{2}$ are given by equations (8) and (13), respectively.

\section{Seasonal Performance Factor}

We may define a Seasonal Performance Factor (SPF) in terms of $\left(M / M_{p}\right)$, where $M_{p}$ is the fuel mass that would have been consumed by a (physically unobtainable) "perfect" system $(\bar{\eta}=1)$. To find the value of

$$
M_{p}=\left(M_{1}\right)_{p}+\left(M_{2}\right)_{p}
$$

We note that $\left(M_{1}\right)_{p}$ and $\left(M_{2}\right)_{p}$ are obtained from equations (8) and (13) by setting all $\eta$ values equal to unity.

The Seasonal Performance Factor may be taken as a "figure of merit." We may then choose to define it as follows:

$$
(\mathrm{SPF}) \equiv \frac{M_{p}}{M}
$$

Correspondingly, we may define a seasonal cost Factor (SCF) as follows:

$$
(\mathrm{SCF})=(\mathrm{SPF})^{-1}
$$

The (SCF) is a direct measure of the annual costs of a given system, relative to a "perfect" one.

The use of the foregoing relations to determine (SPF) is straightforward, once sufficient experimental data are obtained to determine $\eta_{s^{\prime}} \eta_{c^{\prime}} \eta_{c^{\prime}}^{*} \dot{\mathrm{m}}_{f, d^{*}}$ The required device parameters are determined for a given boiler/furnace through a series of laboratory tests. These parameters are currently measured at Brookhaven National Laboratory as part of its boiler/furnace testing program.

It is interesting to note that the overfiring factor, $\alpha$, generally ${ }^{2,4}$ degrades $\bar{\eta}$ and $\bar{\eta}^{*}$ for values of $\alpha>1$. $\bar{\eta}$ and $\bar{\eta}^{*}$ are generally increased for an "underfired" $(\alpha<1)$ device. only for 
the case of a "perfect" device $\left(\bar{\eta}=\bar{\eta}^{*}=1\right)$, does the mass of fuel used seasonally become independent of the value of $\alpha$. This result is seen by an examination of equations (8) and (13). For real devices, the right-hand sides of equations (8) and (13) are implicitly dependent on $\dot{\mathrm{m}}_{f}$ and $\dot{\mathrm{m}}_{f^{\prime}}^{*}$ respectively. These implicit relations derive from the facts expressed by equation (3) . However, for a "perfect" system, all $\eta$ values are equal to unity, and this implicit r.h.s. dependence on $\dot{m}_{f}$ no longer applies. Finally, we recall that equation (3) is not only dependent on the parameters shown, but also depends on the characteristic cycle features of the heating system. 2,3

\section{Some concluding Remarks}

The formulation given in this report can be employed, in conjunction with experimental boiler/furnace data to determine the intrinsic merits of the given device. That is, $\eta_{s}$ and $\eta_{c}$ can be determined for a given characteristic cycle and a given firing rate. The performance of a given device under field conditions involves additional considerations. These too are examined. It is found that the Seasonal Performance Factor (SPF) will depend upon the aforementioned parameters as well as those which characterize the sizing of the device (vis-a-vis the detailed seasonal weather pattern and the design requirements of the conditioned space). The overfiring of the boiler/furnace, where dictated by domestic hot water requirements, tends to degrade the seasonal Performance Factor (SPF). The increase in the seasonal cost Factor (SCF) which results from overfiring, as well as the effects of other parametric variations, is directly calculable from this formulation. 
V. Nomenclature

$\mathrm{H}_{\mathrm{O}}$ - Domestic hot water load (Btu/hr)

$L_{d}$ - Design heat loss load for conditioned space (Btu/hr)

$\stackrel{\circ}{f}_{f}:-$ Mass flow rate of fuel, actual $(1 \mathrm{bs} / \mathrm{hr})$

$\stackrel{\circ}{\mathrm{m}}_{\mathrm{f}, \mathrm{d}}-$ Mass flow rate of fuel, design $(1 \mathrm{bs} / \mathrm{hr})$

$\dot{\mathrm{m}}_{f}^{*}$ - Mass flow rate of fuel during the nonheating season, actual (1bs/hr)

M - Total mass of fuel used during the year (1bs)

$M_{1} \quad$ - Total mass of fuel used during the heating season (1bs)

$\mathrm{M}_{2}$, - Total mass of fuel used during the nonheating season (1bs)

$M_{1 p}$ - Total mass of fuel that would be used during the heating season by a (perfect) system for which all $\eta$ values are unity (1bs)

$\mathrm{M}_{2 \mathrm{p}}$ - Total mass of fuel that would be used during the nonheating season by a (perfect) system for which all $\eta$ values are unity (1bs)

$\mathrm{n}_{i}-$ Number of hours in the year having a characteristic outdoor temperature, $\mathrm{T}_{\mathrm{Ci}}$ ' during the heating season $\left(T_{C, i} \leqslant T^{*}\right)$.

$\mathrm{n}^{*}:-$ Total number of hours in the nonheating season $\left(\mathrm{T}_{\mathrm{C}} \geq \mathrm{T}^{*}\right)$

$\mathrm{T} \quad-\quad$ Temperature $\left({ }^{\circ}\right)$

$T_{c}$ - Characteristic outside temperature $\left({ }^{\circ} \mathrm{R}\right)$

$\mathrm{T}_{\mathrm{C}, \mathrm{i}}$ - Characteristic outside temperature of the $i^{\text {th }}$ value $\left({ }^{\circ} \mathrm{R}\right)$

$\mathrm{T}_{\mathrm{d}}$ - Outside temperature used for design heat loss calculations for the conditioned space $\left({ }^{\circ}\right)$

$T^{*}-$ Temperature of the conditioned space $\left({ }^{\circ} R\right)$ 


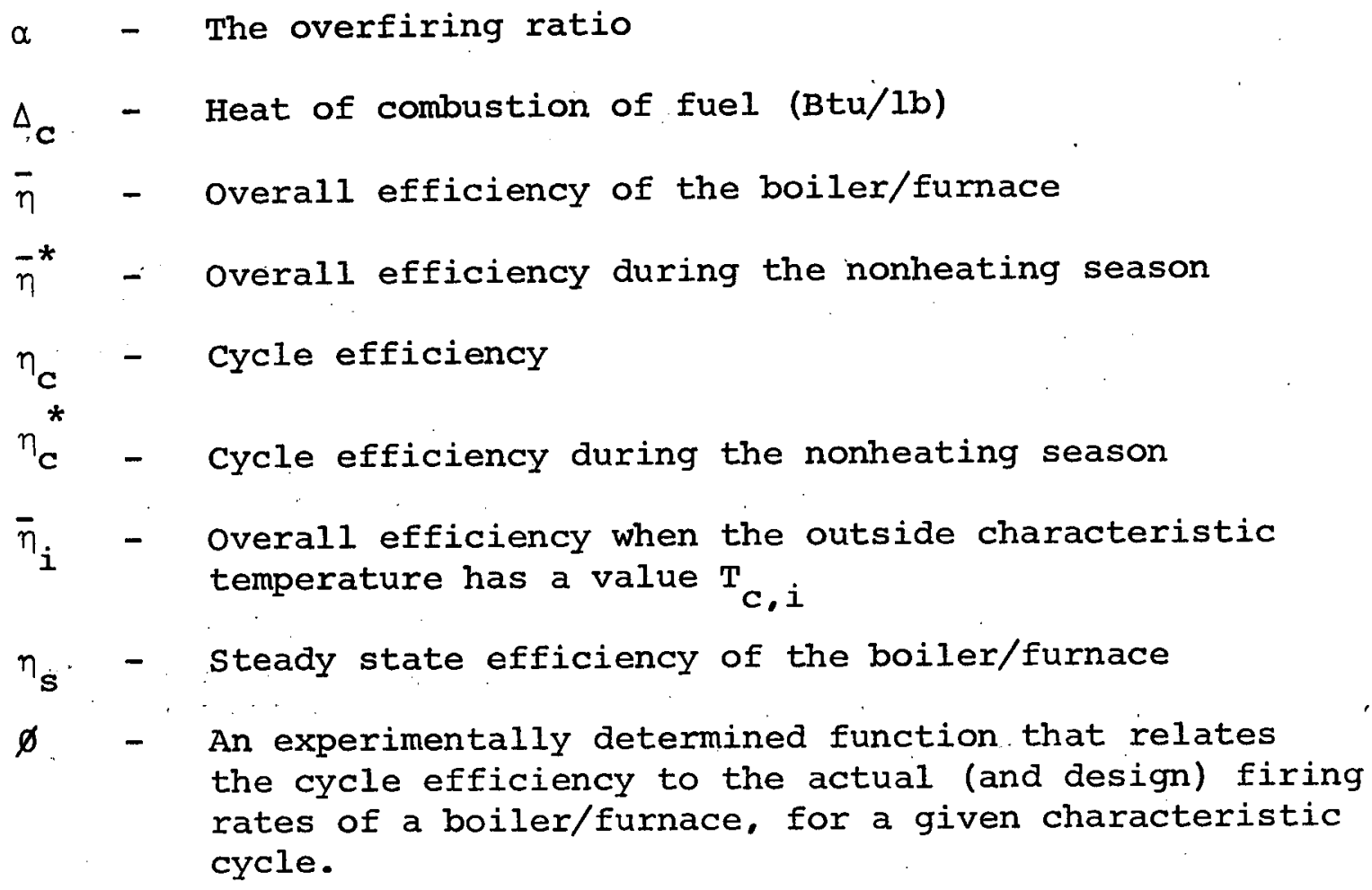
the cycle efficiency to the actual (and design) firing rates of a boiler/furnace, for a given characteristic cycle. 
VI. References

1. Berlad, A. I., and Batey, J. Performance Evaluation and Economic Impact of Oil-Fired Residential Heating. J. Urban Analysis 1. 95 (1972).

2. Berlad, A. I., Salzano, F. J., and Batey, J. On Enthalpy Management in Small Buildings. ENERGY - The International Journal (In Press - to appear November 1976). BNL 20572 and BNL 21577.

3. Berlad, A. L.. Lin, H. C., Salzano, F. J.. and Batey, J. Comfort Range Thermal storage. BNL 21591 (July 1976). To appear Trans. ASME.

4. Bonne, U., Johnson, A. E., Glatzel, J. and Torbor, R. Analysis of New England Oil Burner Data. Effect of Reducing Excess Firing Rate on Seasonal Efficiency. Final report by Honeywell Corporate Research Center on NBS Contract 514736 (August 29, 1975). 